ISSN 2075-4701

www.mdpi.com/journal/metals/

Article

\title{
Modeling of TiAl Alloy Grating by Investment Casting
}

\section{Yi Jia ${ }^{1,2}$, Shulong Xiao ${ }^{1,2}$, Jing Tian ${ }^{2}$, Lijuan $\mathrm{Xu}^{2}$ and Yuyong Chen ${ }^{1,2,3, *}$}

1 National Key Laboratory of Science and Technology on Precision Heat Processing of Metals, Harbin Institute of Technology, Harbin 150001, China; E-Mails: samuel_jia@ hotmail.com (Y.J.); xiaoshulong@hit.edu.cn (S.X.)

2 School of Materials Science and Engineering, Harbin Institute of Technology, Harbin 150001, China; E-Mails: tianjing@ hit.edu.cn (J.T.); xljuan@hit.edu.cn (L.X.)

3 State Key Laboratory of Advanced Welding and Joining, Harbin Institute of Technology, Harbin 150001, China

* Author to whom correspondence should be addressed; E-Mail: yychen @ hit.edu.cn;

Tel./Fax: +86-451-8641-8802.

Academic Editor: Ana Sofia Ramos

Received: 19 October 2015 / Accepted: 4 December 2015 / Published: 9 December 2015

\begin{abstract}
The investment casting of TiAl alloys has become the most promising cost-effective technique for manufacturing TiAl components. This study aimed to investigate a series of problems associated with the investment casting of TiAl alloys. The mold filling and solidification of this casting model were numerically simulated using ProCAST. Shrinkage porosity was quantitatively predicted by a built-in feeding criterion. The results obtained from the numerical simulations were compared with experiments, which were carried out on Vacuum Skull Furnace using an investment block mold. The investment casting of TiAl grating was conducted for verifying the correctness and feasibility of the proposed method. The tensile test results indicated that, at room temperature, the tensile strength and elongation were approximately $675 \mathrm{MPa}$ and $1.7 \%$, respectively. The microstructure and mechanical property of the investment cast $\mathrm{TiAl}$ alloy were discussed.
\end{abstract}

Keywords: numerical simulation; TiAl alloys; investment casting; shrinkage porosity 


\section{Introduction}

Energy as well as environmental issues have become the main obstacles for sustaining social and economic development. The substitution of lightweight materials for heavy ones is effective for solving this problem. Aviation and aerospace materials are developed with a predominant focus on the development of lightweight, high-strength materials. TiAl alloys exhibit excellent mechanical, oxidation, and corrosion resistance properties at elevated temperatures (greater than $600{ }^{\circ} \mathrm{C}$ ), making them a possible replacement for traditional $\mathrm{Ni}$-based superalloy components in the aircraft and automobile industry for increasing the thrust-to-weight ratio and efficiency while decreasing exhaust and noise pollution [1-3]. Because of the chemical heterogeneity and physical properties of TiAl alloys, numerous efforts have been focused on the introduction of titanium aluminide into the market, albeit with limited success. A limitation for the "mass market" manufacture of TiAl-based components is that TiAl exhibits very high chemical reactivity, high melting temperature, low ductility, and poor workability. In contrast, casting exhibits a significant advantage for complex-shaped components such as turbine blades, turbocharger rotators and exhaust valves. Because of these issues, investment casting, which can directly produce near-net-shaped components with a good surface finish and low production cost, is a subject of growing interest [4].

Different casting processes are employed for casting TiAl alloys, such as induction-skull melting (ISM), vacuum-arc remelting (VAR), counter-gravity low pressure atmosphere melting (CLIM), plasma-arc melting (PAM), etc. Although most of these processes produce high quality castings, the cost of the products is rather high.

Investment casting exhibits tremendous advantages for the production of quality cast components as it has the key benefits of accuracy, versatility and integrity. As a result, investment casting is one of the most economical methods for producing a wide range of metal castings.

Several efforts have been focused on the thermodynamic stability and mechanism of interaction between refractory materials such as $\mathrm{CaO}[5,6], \mathrm{Al}_{2} \mathrm{O}_{3}[7,8], \mathrm{ZrO}_{2}[9,10]$ and $\mathrm{Y}_{2} \mathrm{O}_{3}[11,12]$ in contact with molten TiAl alloys. Such information is of great interest not only for the purpose of solidification studies but also for the induction melting of TiAl alloys and their investment casting in ceramic molds as well.

The casting process based on experience has the characteristics of high cost and long cycle. In addition, the pouring process is invisible. However, by numerical simulation, cost savings as well as a reduction in production cycles can be achieved. Signification promise and potential have been demonstrated by numerical simulations. This study aims to fabricate a grating with $\mathrm{Ti}-47 \mathrm{Al}-2.5 \mathrm{~V}-1 \mathrm{Cr}$ (at. \%) by investment casting and discusses the relevant microstructure and mechanical properties.

\section{Experimental Section}

The casting of the TiAl alloy grating was a disk with a diameter of $580 \mathrm{~mm}$, which had a $180 \mathrm{~mm}$ hole in the center, and a thickness of $10 \mathrm{~mm}$. Initially, we made a small test disk with a diameter of $400 \mathrm{~mm}$, which had a $120 \mathrm{~mm}$ hole in the center, and a thickness of $10 \mathrm{~mm}$. In the following text, we refer to full-size casting as the ultimate goal, and test casting as the minor one. All samples for characterization were cut from the test casting. The full-size casting only employed X-ray non-destructive inspection for the porosity in the casting. 


\subsection{Numerical Simulation}

Experiment processes of TiAl casting were simulated by a finite element method (FEM) software ProCAST package (ESI Group, Paris, France). Tables 1 and 2 summarize the thermo-physical material properties of the casting and mold, respectively, which were implemented in the preprocessing procedure; the properties of TiAl were given by Sung [13,14], and the properties of $\mathrm{ZrO}_{2}$ were given by ProCAST. The environment temperature in Table 2 was the temperature in the vacuum chamber during melting because it is too difficult to calculate the heat effect of the melting system to the environment. So, we ignored that, and determined it to be room temperature. The filling and solidification behavior was simulated by the calculation procedure. The filling behavior, temperature field and solidification parameters, with respect to the formation of shrinkage porosity, were analyzed during the post-processing procedure. The initial processing parameters used in the simulation were a pouring temperature of $1700{ }^{\circ} \mathrm{C}$, and a filling time of $3 \mathrm{~s}$.

Table 1. Thermo-physical properties of TiAl alloy varied with temperature.

\begin{tabular}{ccccc}
\hline $\begin{array}{c}\text { Temperature/ } \\
\left({ }^{\circ} \mathbf{C}\right)\end{array}$ & $\begin{array}{c}\text { Density/ } \\
\left(\mathbf{k g} \cdot \mathbf{m}^{-\mathbf{3}}\right)\end{array}$ & $\begin{array}{c}\text { Specific Heat/ } \\
\left(\mathbf{J} \cdot \mathbf{k g}^{-\mathbf{1}} \cdot \mathbf{K}^{\mathbf{- 1}}\right)\end{array}$ & $\begin{array}{c}\text { Thermal Conductivity/ } \\
\left(\mathbf{W} \cdot \mathbf{m}^{-\mathbf{1}} \cdot \mathbf{K}^{-\mathbf{1}}\right)\end{array}$ & $\begin{array}{c}\text { Thermal Diffusion/ } \\
\left(\mathbf{m}^{\mathbf{2}} \cdot \mathbf{s}^{\mathbf{- 1}}\right)\end{array}$ \\
\hline 25 & 3857 & 598 & 13.2 & - \\
200 & - & 630 & 16.7 & - \\
400 & - & 667 & 20.2 & - \\
600 & - & 703 & 23.1 & - \\
700 & - & 799 & 25.4 & 8.4 \\
800 & - & 769.3 & 26.8 & 8.8 \\
900 & - & 900.1 & 28. & 8.1 \\
1000 & - & 975.9 & 27.9 & 7.7 \\
1100 & - & 995.6 & 26.5 & 7.2 \\
1200 & - & 1140.4 & 27.3 & 6.7 \\
1600 & 3788 & 786 & 31 & - \\
1800 & 3612 & 794 & 37 & - \\
\hline
\end{tabular}

Table 2. Thermo-physical properties of TiAl alloy and $\mathrm{ZrO}_{2}$ mold.

\begin{tabular}{ccc}
\hline Thermophysical Properties & TiAl Alloy & Mold $\left(\mathbf{Z r O}_{2}\right)$ \\
\hline Density $/\left(\mathrm{kg} \cdot \mathrm{m}^{-3}\right)$ & 3788 & 3970 \\
Specific heat $/\left(\mathrm{J} \cdot \mathrm{kg}^{-1} \cdot \mathrm{K}^{-1}\right)$ & 598 & 777 \\
Thermal conductivity $/\left(\mathrm{W} \cdot \mathrm{m}^{-1} \cdot \mathrm{K}^{-1}\right)$ & 13.2 & 39 \\
Liquidus temperature $/\left({ }^{\circ} \mathrm{C}\right)$ & 1554 & 2323 \\
Solidus temperature $/\left({ }^{\circ} \mathrm{C}\right)$ & 1478 & - \\
Latent heat $/\left(\mathrm{J} \cdot \mathrm{kg}^{-1} \cdot \mathrm{K}^{-1}\right)$ & 435 & - \\
Environment temperature $/\left({ }^{\circ} \mathrm{C}\right)$ & 25 & 25 \\
\hline
\end{tabular}

\subsection{Production of Castings}

The alloy used in this study had a nominal composition of $\mathrm{Ti}-47 \mathrm{Al}-2.5 \mathrm{~V}-1 \mathrm{Cr}$ (at. \%, TiAl alloy hereafter). The castings were produced by VAM-150, ZXVAC (Shenyang, China). The charge material was pieces of TiAl alloy ingots produced by vacuum-arc remelting. 
In this study, the conventional "lost wax" procedure was employed for fabricating ceramic shell molds. The replicated wax crowns were assembled on the numerically optimized runner and gating system.

The detailed manufacturing processes were described as follows. First, the wax patterns were dipped into the slurry, which was mixed with zirconia sol and $\mathrm{ZrO}_{2}$ powders (diameter $<50 \mu \mathrm{m}$ ), stuccoed by zirconia sand and dried. After the primary coating, wax patterns were coated with a back-up slurry, which comprised alumina and silica sol. Back-up coating process was repeated several times for enhancing the strength of the ceramic molds. Finally, a sealing coat of the back-up slurry was applied. At the end of these processes, the total thickness of the ceramic molds was 7-10 mm. The de-waxing process of the ceramic molds was carried out at about $0.8 \mathrm{MPa}$ and $150{ }^{\circ} \mathrm{C}$ in a steam autoclave. After de-waxing, the ceramic molds were sintered at $950{ }^{\circ} \mathrm{C}$ for $2 \mathrm{~h}$.

Molds were kept in a refractory-filled can, the vacuum chamber was evacuated and backfilled with argon at a pressure of $8 \times 10^{4} \mathrm{~Pa}$ and the charge melted. Prior to the pouring process, the ceramic molds were first preheated, and then molten TiAl was poured into the preheated ceramic molds. After removing the ceramic molds, TiAl castings were obtained. There are some negative factors in TiAl casting, such as the static pressure head is low because of low density $\left(3.8 \mathrm{~g} / \mathrm{cm}^{-3}\right)$, narrow solidification interval $\left(<80{ }^{\circ} \mathrm{C}\right)$, and bad fluidity. Hence, there is a tendency to employ a pouring temperature as high as possible for improving the quality of the TiAl casting. The machine can melt $\mathrm{TiAl}$ at the highest temperature $1700{ }^{\circ} \mathrm{C}$; hence, it is chosen as the pouring temperature.

\subsection{Characterization of Microstructure and Mechanical Property}

Samples used for characterization were cut from the test casting. All microstructures had been ground and polished electrolytically (Perchloric 6\% + Butoxyethanol 34\% + Methanol 60\%, $-30{ }^{\circ} \mathrm{C}, 35 \mathrm{~V}$, $9 \mathrm{~mA}$ ). Metallographic specimens were etched by Kroll's reagent (a mixture of $10 \mathrm{~mL} \mathrm{HF,} 5 \mathrm{~mL} \mathrm{\textrm {HNO } _ { 3 }}$ and $85 \mathrm{~mL} \mathrm{H} \mathrm{H}_{2} \mathrm{O}$ ) for observation under an optical microscope. Optical microscopy was performed with an Olympus microscope (Tokyo, Japan). The mechanical property of the castings was characterized by tensile deformation experiments at a constant strain rate $\left(1 \times 10^{-4} \mathrm{~s}^{-1}\right)$ performed at room temperature. A field emission gun scanning electron microscope (SEM, FEI, QUANTA 200F, Portland, OR, USA) was employed for characterizing the morphologies of the fracture surface.

\section{Results and Discussion}

\subsection{Numerical Simulation for Test Casting}

The three-dimensional (3D) model of test casting based on the first design is shown in Figure 1. The mold-filling process and solidification were calculated. All the casting gratings exhibited porosities under different initial conditions, as shown in Figure 2. The results indicated that casting defects are spread throughout the entire cast gratings, and the porosity is considerable. Casting defects are affected by the mold-filling process and the solidification of the cast grating. For a mold temperature of $25{ }^{\circ} \mathrm{C}$ and gravity casting, the worst results are obtained from the simulation (Figure 2a), and a large amount of shrinkage pores are spread throughout the entire cast grating. With the increase in the mold temperature to $800{ }^{\circ} \mathrm{C}$, the situation improves slightly (Figure 2b). Moreover, when a centrifugal casting is employed, the situation significantly improves at rotation speeds of $200 \mathrm{rpm}$ and $400 \mathrm{rpm}$ 
(Figure 2c-f). However, with the increase in the rotation speed to $600 \mathrm{rpm}$, the amount of shrinkage pores increases (Figure 2g,h).

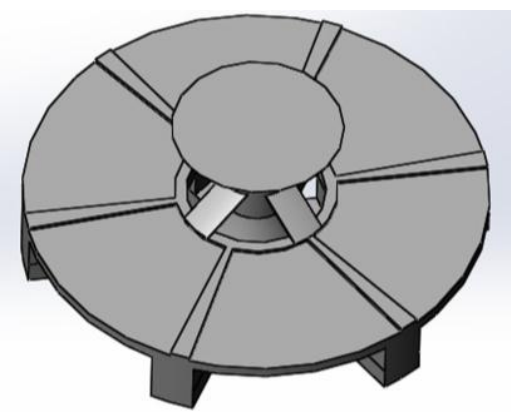

Figure 1. Three-dimensional drawing of runner system for test casting.
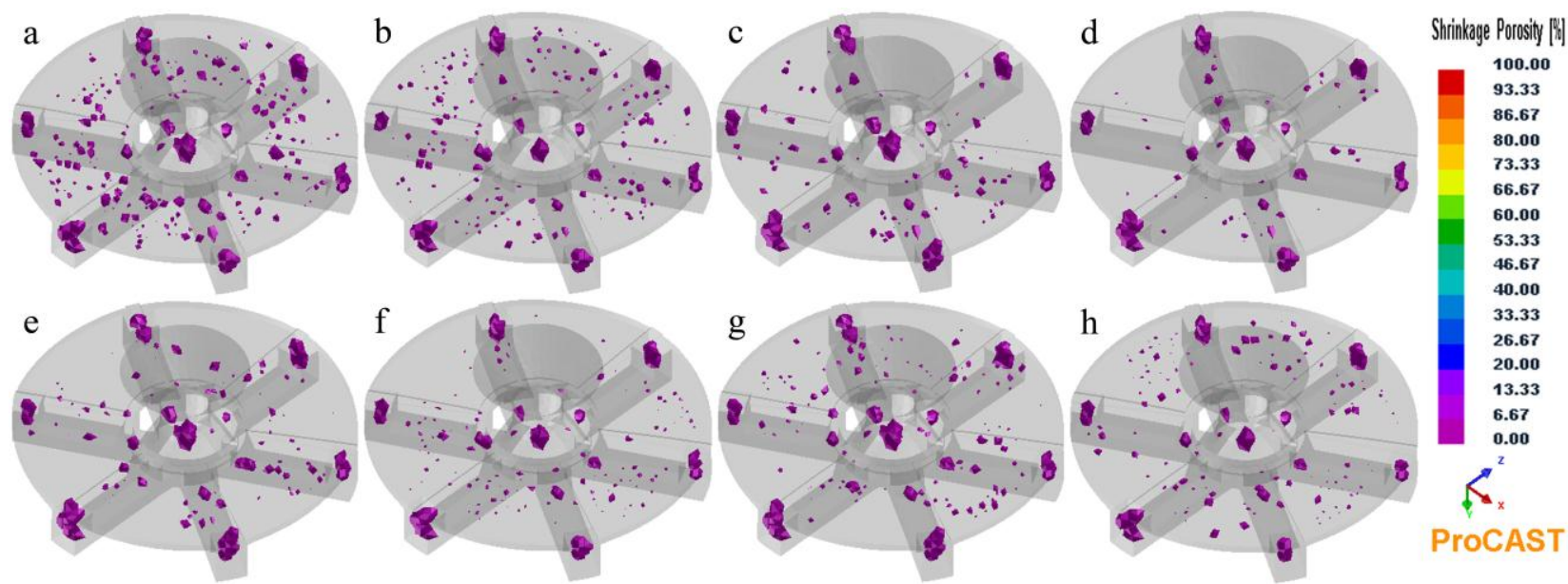

Figure 2. The predicted shrinkage porosity of test castings: (a) mold temperature of $25{ }^{\circ} \mathrm{C}$ and gravity casting (short for $25^{\circ} \mathrm{C}, 0 \mathrm{rpm}$ ); (b) $800{ }^{\circ} \mathrm{C}, 0 \mathrm{rpm}$; (c) $25^{\circ} \mathrm{C}, 200 \mathrm{rpm}$; (d) $800{ }^{\circ} \mathrm{C}$, $200 \mathrm{rpm}$; (e) $25^{\circ} \mathrm{C}, 400 \mathrm{rpm}$; (f) $800{ }^{\circ} \mathrm{C}, 400 \mathrm{rpm}$; (g) $25^{\circ} \mathrm{C}, 600 \mathrm{rpm}$; (h) $800{ }^{\circ} \mathrm{C}, 600 \mathrm{rpm}$.

Because of the contact with the mold, the front-flowing molten metal loses a large amount of heat, which causes a sudden decrease in temperature, and the molten metal may no longer flow to the cold end of the mold. The possibility of shrinkage porosity slightly decreased with a high mold temperature. For a given pouring temperature and mold temperature, the molten TiAl alloy fills the mold at a rapid rate, it gets a long time to feed, and decreases the possible formation of cast defects. In the case when the pouring rate is limited by the casting equipment, the action of the centrifugal force results in the spreading of the molten metal. With this runner design, the liquid flow would break under excessive centrifugal force; hence, a high rotation speed causes deterioration instead (Figure 2g,h). When the temperature of the frontier molten metal rapidly decreases, a large number of dendrites would mix in with the molten alloy, which would increase the viscosity of the molten alloy and flow resistance, slowing down of the flow rate of the molten alloy. While centrifugal force stirs the molten alloy, dendrites mixed with the latter molten alloy with higher temperature for remelting. By comparing the two cases, a mold temperature of $25^{\circ} \mathrm{C}$ and gravity casting and a mold temperature of $800{ }^{\circ} \mathrm{C}, 400 \mathrm{rpm}$, when the mold is completely filled, the solid fractions obtained are $11.3 \%$ and $0.2 \%$, respectively. 
For shrinkage porosity, Figure $2 \mathrm{~d}$ showed best situation, Figure $2 \mathrm{f}$ was the second and Figure $2 \mathrm{e}$ was the third. However, Figure 3d,e exhibited voids, and Figure $3 \mathrm{f}$ was free of voids. In ProCAST, the voids predicted represent not only air bubbles but also oxide layers trapped in areas where fluid flow is restricted. Hot Isostatic Pressing (HIP), which is a necessary step in the foundry industry, can eliminate voids but does not remove micro-porosity, which means that voids are more serious than porosity. Hence, a mold temperature of $800{ }^{\circ} \mathrm{C}$ and a rotation speed of $400 \mathrm{rpm}$ are probably good choices for the test casting, which exhibited porosity slightly more than that observed at a mold temperature of $800{ }^{\circ} \mathrm{C}$ and a rotation speed of $200 \mathrm{rpm}$, albeit free of voids.
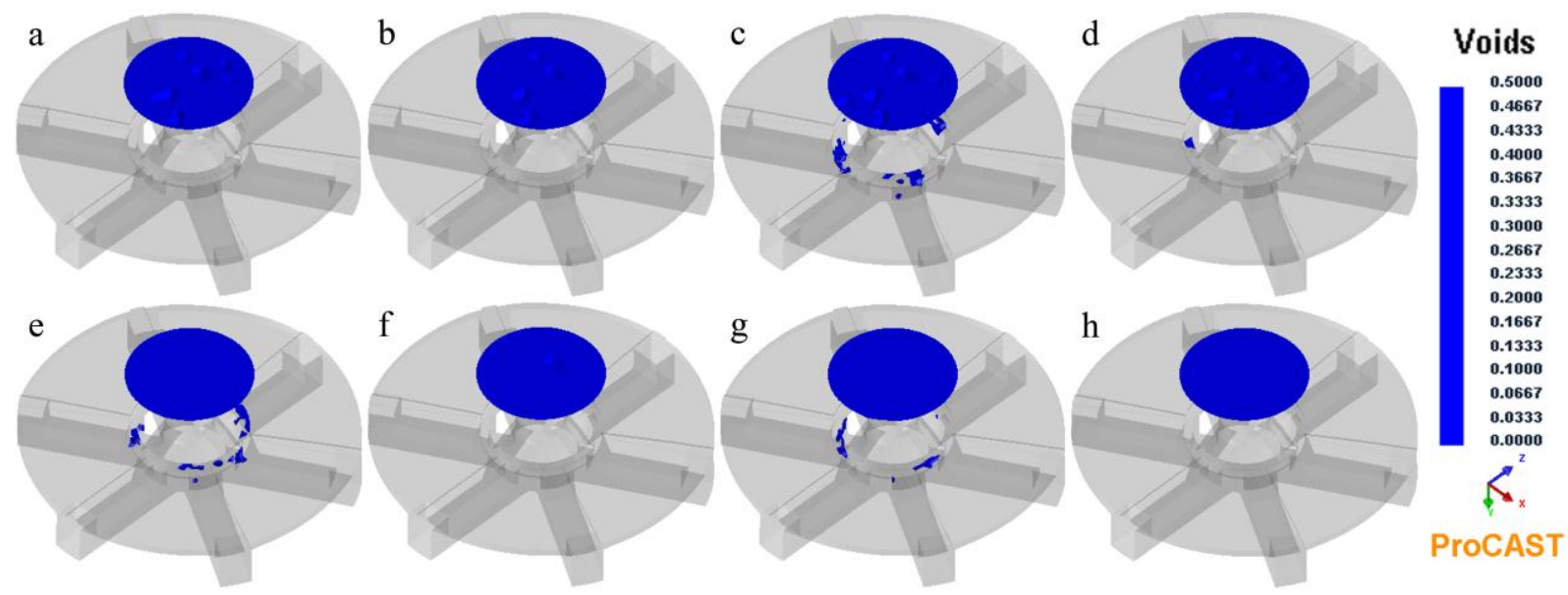

Figure 3. Predicted voids of test castings, $(\mathbf{a}-\mathbf{h})$, the same as the Figure 2.

\subsection{The Quality of Test Casting}

Figure 4a shows TiAl alloy test castings, which show visible pores on the surface. Figure $4 \mathrm{~b}$ shows the location of the samples for metallographic observation and tensile test. As shown in Figures 5 and $6 \mathrm{c}, \mathrm{d}$, the orientation of the metallographic section is tangential, and Figure 6a shows the contact surface between the disk and runner.
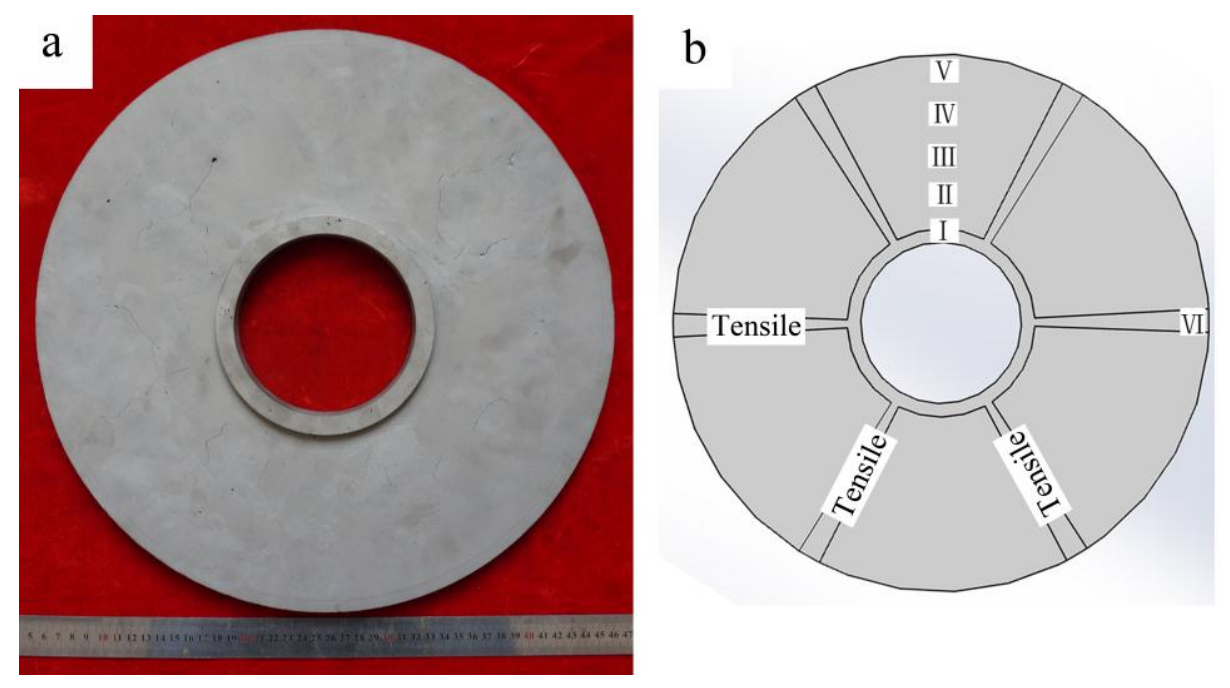

Figure 4. Test casting (a,b) showed the specimen locations: I, II, III, IV, and V, for Figure 5a-e, respectively; VI for Figure 6a; Tensile for the tensile test. 

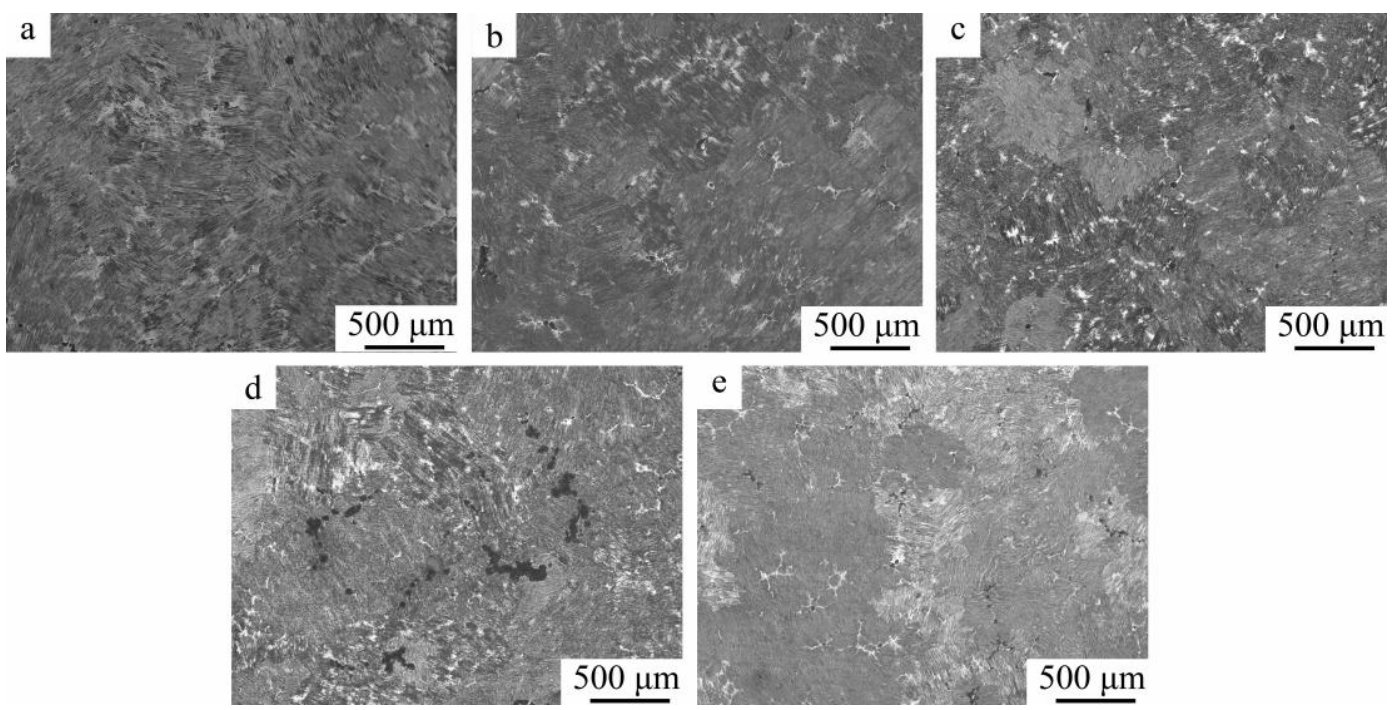

Figure 5. Optical microstructure of test casting $(\mathbf{a}-\mathbf{e})$ were from the center hole to the outer edge, and the interval between the two samples measured $20 \mathrm{~mm}$.

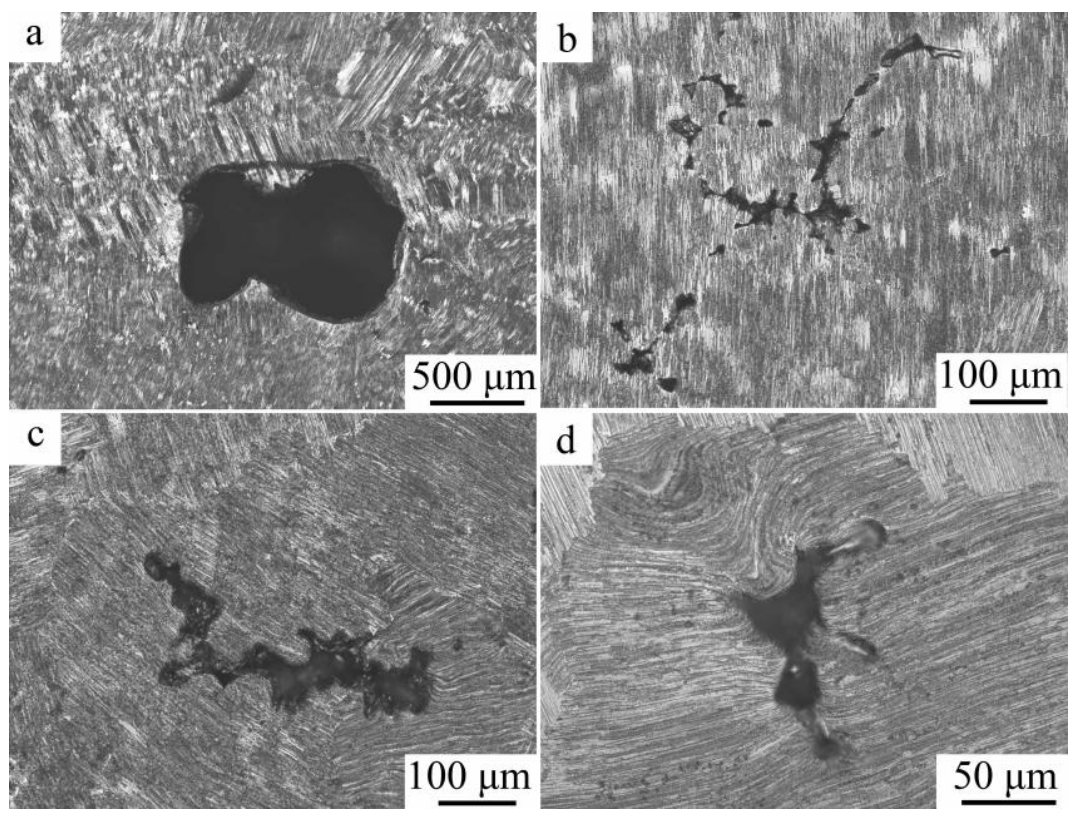

Figure 6. Micro-defects of test casting, (a) pore and (b-d) shrinkage.

Figure 5 shows a typical fully lamellar microstructure of as-cast TiAl, which contains a small amount of finely segregated $\gamma$-grains which are mainly located at the lamellar grain boundaries or in the interdendritic region as a result of the occurrence of double peritectic reactions during solidification. The microstructure does not significantly differ from the center hole to the outer edge; however, the casting defects are not the same everywhere. Figure 5a,b,e show micropores, and Figure 5c,d show extensive micro-porosity. Compared with the simulation data as shown in Figure $2 \mathrm{~d}$, the predicted shrinkage porosity of casting is in agreement with the experimental data, which show that the shrinkage porosity of casting enriches in the center of the casting and is absent near the center hole and outer edge. Figure 6a shows that a big hole appeared in runner, which is proved by Figure 7b. Figure 6a,b show that there is no effect of shrinkage on the fully lamellar microstructure; however, Figure $6 \mathrm{c}, \mathrm{d}$, show bending lamellar microstructure near the shrinkage. Figure $7 \mathrm{a}$ shows the slice view of the disk, and Figure $7 \mathrm{~b}$ 
shows the slice view of the rib. As shown in Figure 7a, marginal shrinkage porosity is observed, and the amount of shrinkage porosity is significantly less than that in Figure 7b. The predicted shrinkage porosity by ProCAST is the probability, and Figure 5 meets the left half of Figure 7a-Figure 5a,b,e is almost porosity free, Figure 5c shows a few pores, and Figure 5d shows enrichment of shrinkage porosity.

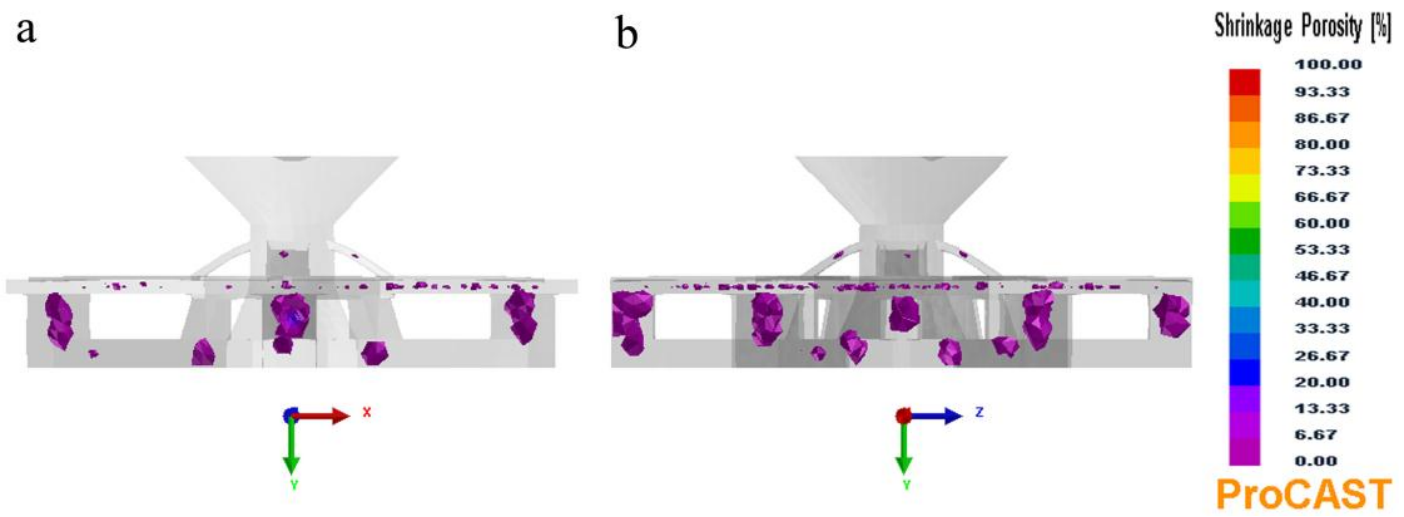

Figure 7. Slice view at a mold temperature of $800{ }^{\circ} \mathrm{C}$ and rotation speed of $400 \mathrm{rpm}$, (a) disk and (b) rib.

\subsection{Mechanical Property for Test Casting}

Figure 8a shows the mechanical property of the investment cast TiAl alloy at room temperature. The tensile strength and elongation at room temperature are about $675 \mathrm{MPa}$ and $1.7 \%$, respectively. The results obtained from this study are in good agreement with the data reported previously $[4,15]$. The mechanical property of a casting not only depends on its microstructure but also on the alloy composition, casting conditions and heat treatment. Figure $8 \mathrm{~b}$ shows the fracture surface of an investment cast TiAl specimen at room temperature that presents an irregular and tortuous surface. It can be concluded that the main failure modes are inter-granular fracture in equiaxed $\gamma$-grains and trans-lamellar cracking in lamellar grains. The minor failure modes are trans-granular cracking in equiaxed $\gamma$-grains and local ductile failure in lamellar grains. It is suggested that the retained as-cast lamellar structure has a detrimental effect on tensile property, especially elongation. This is mainly related to the strong anisotropic flow stress behavior of the $\alpha 2 / \gamma$ lamellar [2].
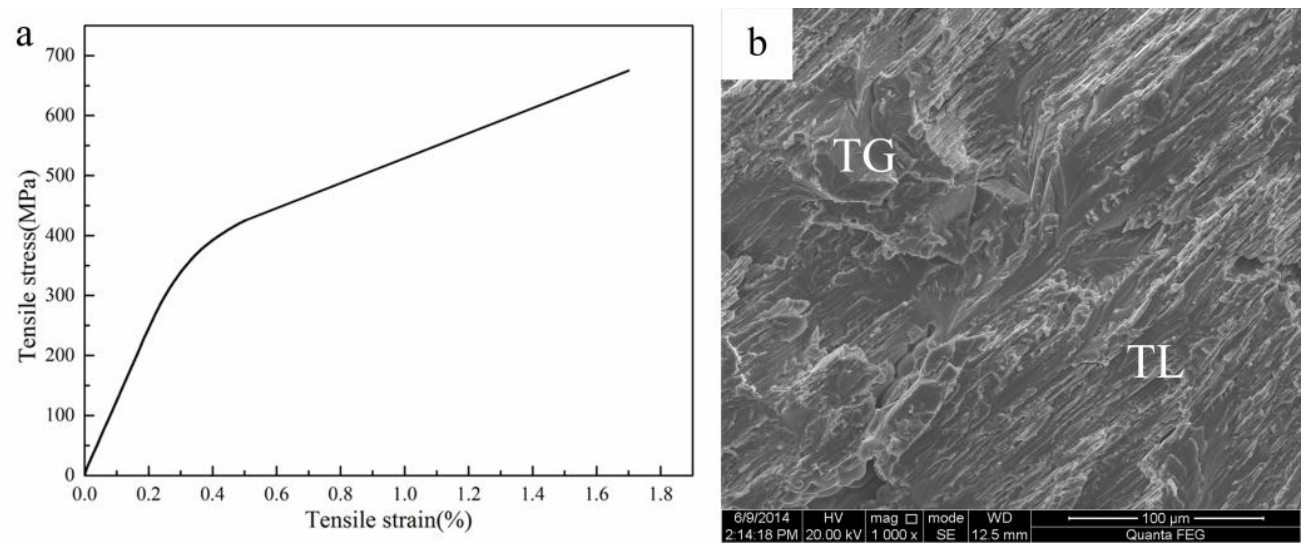

Figure 8. Tensile test stress-strain curve obtained at room temperature (a) and fracture surface (b) of as-cast TiAl specimen, transgranular (TG) and translamellar (TL). 


\subsection{Numerical Simulation for Full-Size Casting}

From simulation results and the microstructure of the test casting, the thickness of the disk is too small to be compared with its diameter. Hence, the mold is hardly full with molten alloy in a gravity cast. However, when a centrifugal force is employed, the molten alloy can be easily torn in the flat disk. In this case, the advantage of centrifugal force is weakened. Hence, the main ideas of improvement with respect to the runner system are to provide a sufficient molten alloy to fill the mold and keep the fluid stable. Therefore, it is decided to moderately increase the gate size, as shown in Figure 9.

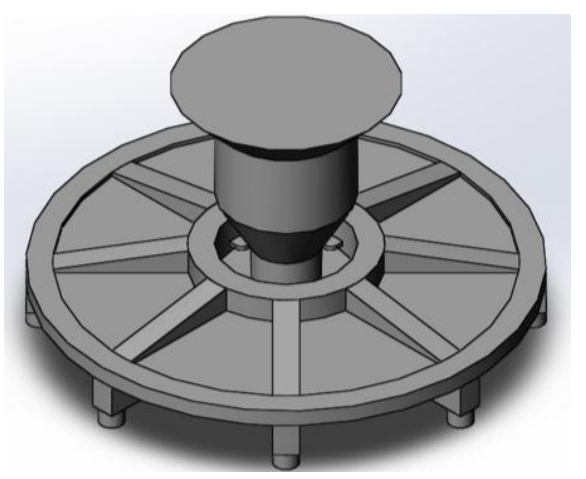

Figure 9. Three-dimensional drawing of runner system for full-size casting.

The simulation results obtained for the test casting show that mold temperature is not a factor that decides the quality of casting below $800{ }^{\circ} \mathrm{C}$. On the other hand, high mold temperature causes a heavy interfacial reaction [13], hence the preheat temperature of the mold for the full-size casting decreases.

Figure 10 shows the shrinkage porosity in the full-size castings: casting defects in the optimized design significantly decrease more when compared to those in the test casting. Because of the enlarged filling gate, the centrifugal effects exhibit dramatic improvement of the mold filling (Figure 10b-e).
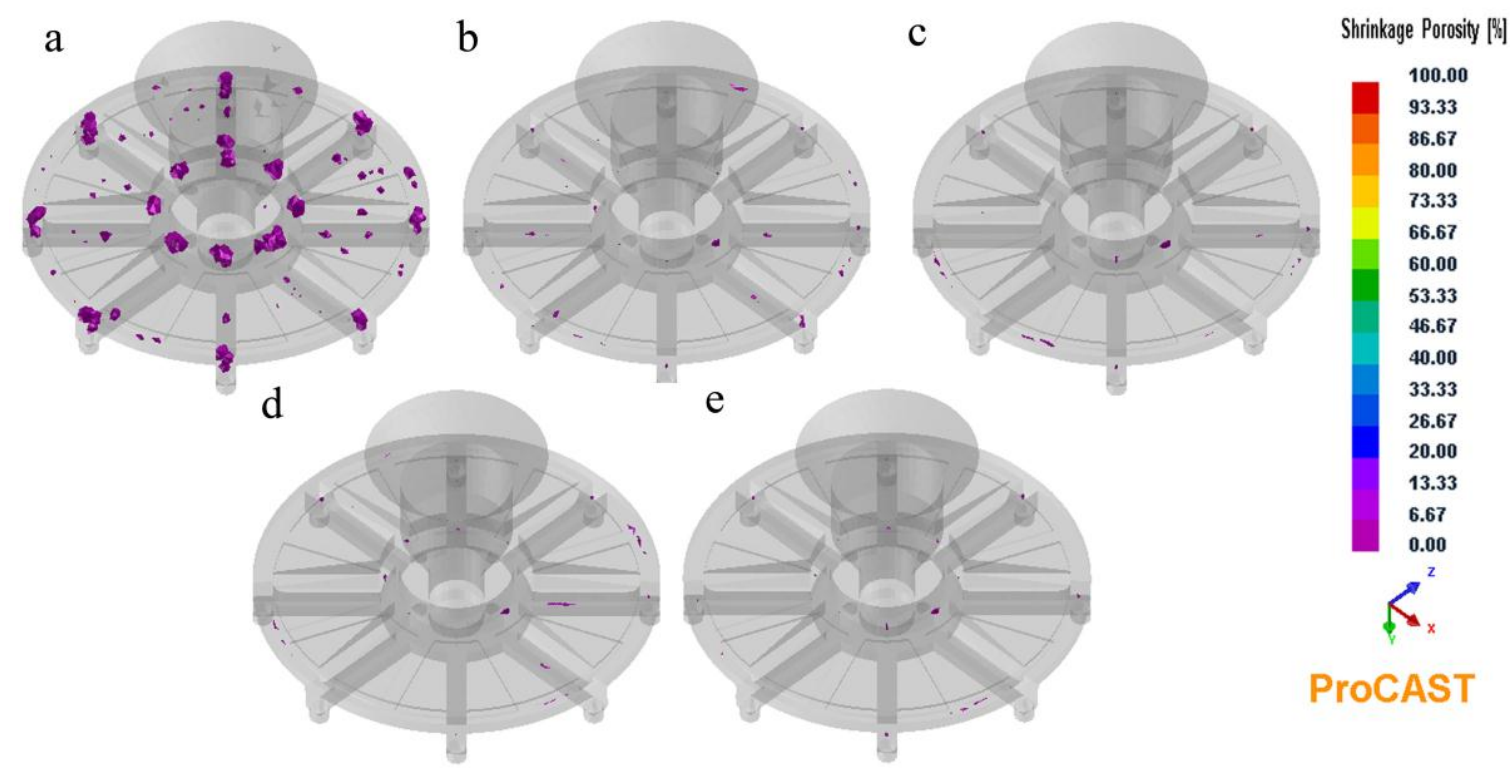

ProCAST

Figure 10. The predicted shrinkage porosity of full-size castings, (a) mold temperature of $600{ }^{\circ} \mathrm{C}$ and gravity casting (short for $600{ }^{\circ} \mathrm{C}, 0 \mathrm{rpm}$ ); (b) $200{ }^{\circ} \mathrm{C}, 200 \mathrm{rpm}$; (c) $400{ }^{\circ} \mathrm{C}, 200 \mathrm{rpm}$; (d) $600{ }^{\circ} \mathrm{C}, 200 \mathrm{rpm}$; (e) $600{ }^{\circ} \mathrm{C}, 400 \mathrm{rpm}$. 
Shrinkage porosity is the result of failure of feeding to operate effectively. In this case, centrifugal force can effectively decrease shrinkage porosity; however, it would produce voids, which are caused by gas trapped in the liquid alloy. Figure 11 shows the voids of the full-size castings. The 10-mm-thick disk is the required component; hence, the voids in the rib and platform are acceptable. The simulation data show that a mold temperature of $600{ }^{\circ} \mathrm{C}$ and rotation speed of $200 \mathrm{rpm}$ are the best choice for the full-size casting. Although it is only slightly better than the other three plans (Figure 11b-e), considering that there are some harmful effects not included in the simulation such as sand hoppers, this marginal advantage is still worth consideration.

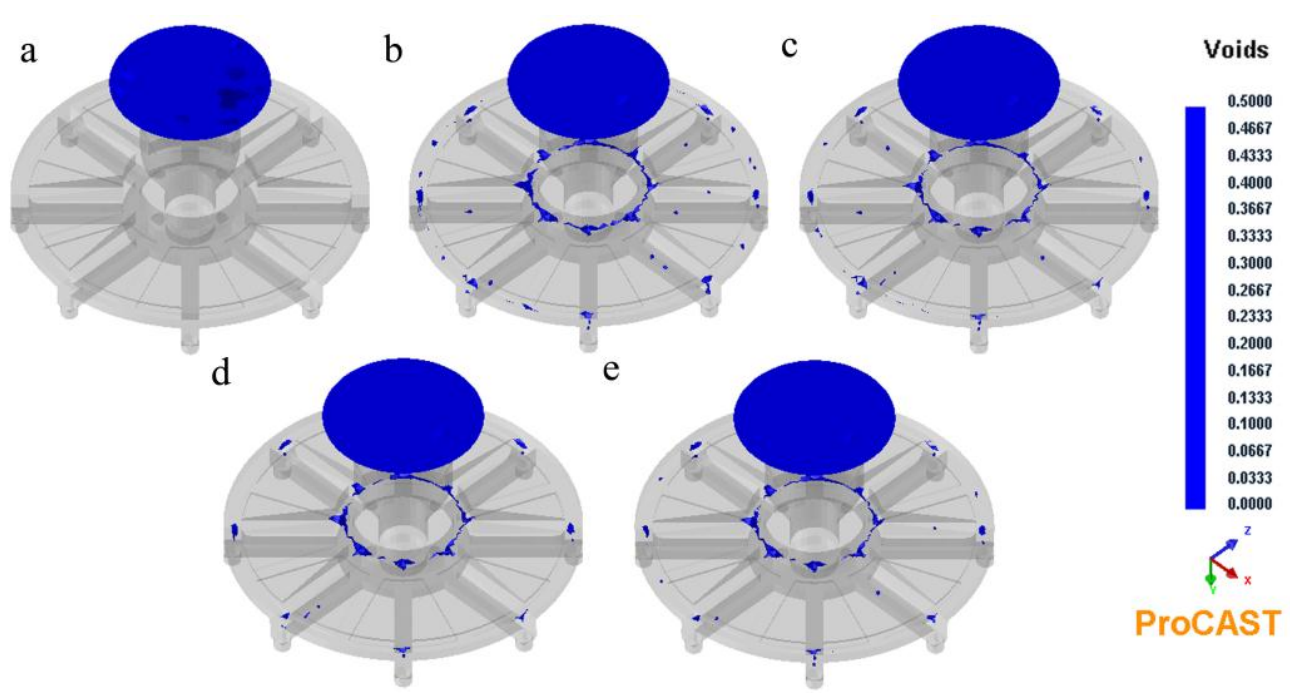

Figure 11. Predicted voids of full-size castings, (a-e) the same as the Figure 10.

As shown in Figure 12a, few pores are observed in the rib, and the surface of the disk is defect-free. Radiography revealed major internal defects present (Figure 12b). As shown in Figure 12c, some micro-porosity is also observed in the disk. The pores exhibit a round, smooth edge; hence, they are blowholes. At a mold temperature of $600{ }^{\circ} \mathrm{C}$ and rotation speed of $200 \mathrm{rpm}$, marginal shrinkage porosity and voids are observed in the simulation (Figures 10d and 11d). We speculate that their presence is attributed to the fact that the permeability of the mold is not sufficient. There is an ideal condition for ProCAST, but not for the experiment. There is also an indication of shrinkage in the junction between the rib and the outer ring of the disk (Figure 12d), which is a hot spot because storage is present under it.
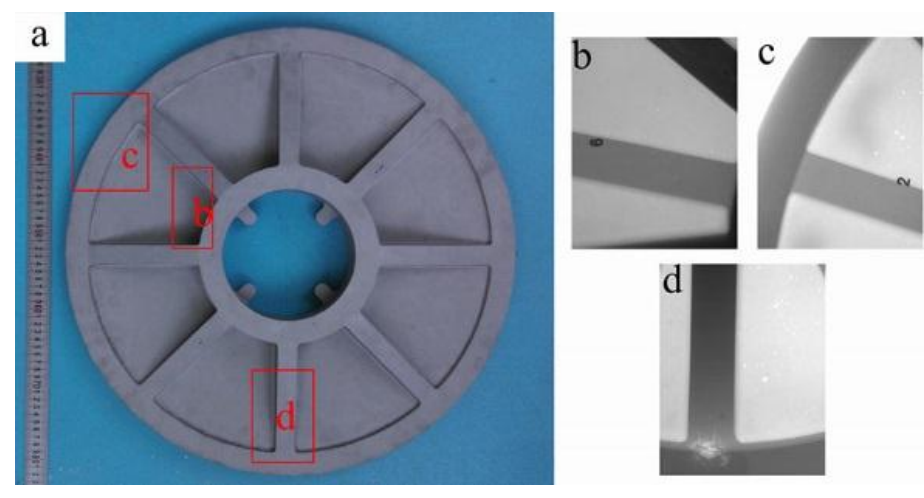

Figure 12. X-ray nondestructive inspection results of full-size casting, (a) the grating casting and (b-d) correspond to b, c and d areas on (a), respectively. 


\section{Conclusions}

The mold-filling and solidification process of TiAl grating by centrifugal investment casting were simulated. The following principal conclusions were drawn from this study:

(1) Gratings with diameters of 400 and $580 \mathrm{~mm}$ were successfully produced.

(2) The casting parameters for the test casting were a pouring temperature of $1700{ }^{\circ} \mathrm{C}$, a mold preheated temperature of $800{ }^{\circ} \mathrm{C}$, and a rotation speed of $400 \mathrm{rpm}$.

(3) The optimal casting parameters for full-size casting were a pouring temperature of $1700{ }^{\circ} \mathrm{C}$, a mold preheated temperature of $600{ }^{\circ} \mathrm{C}$, and a rotation speed of $200 \mathrm{rpm}$.

(4) The specimens showed a typical fully lamellar microstructure, which exhibits finely segregated $\gamma$-grains. TiAl as-cast specimens exhibited a moderate mechanical property. At room temperature, the tensile strength and elongation were about $675 \mathrm{MPa}$ and $1.7 \%$, respectively.

\section{Acknowledgments}

This research was financially supported by the National Natural Science Foundation of China (No. 51001040) and the National Natural Science Foundation of China (No. 51371064).

\section{Author Contributions}

Yi Jia and Yuyong Chen conceived and designed the experiments; Yi Jia and Shulong Xiao performed the experiments; Yi Jia, Lijuan Xu and Jing Tian analyzed the data; Yi Jia wrote the paper.

\section{Conflicts of Interest}

The authors declare no conflict of interest.

\section{References}

1. Kim, Y.W. Gamma-titanium aluminides: Their status and future. J. Miner. 1995, 47, 39-41.

2. Yamaguchi, M.; Inui, H.; Ito, K. High-temperature structural intermetallics. Acta Mater. 2000, 48, 307-322.

3. Varin, R.A.; Gao, Q. The effect of chromium on the microstructure and micromechanical properties of TiAl-base alloys. Mater. Manuf. Process. 1996, 11, 381-410.

4. Kuang, J.P.; Harding, R.A.; Campbell, J. Microstructures and properties of investment castings of $\gamma$-titanium aluminide. Mater. Sci. Eng. A 2002, 329, 31-37.

5. Gomes, F.; Barbosa, J.; Ribeiro, C.S. Induction melting of $\gamma$-TiAl in CaO crucibles. Intermetallics 2008, $16,1292-1297$.

6. Tsukihashi, F.; Tawara, E.; Hatta, T. Thermodynamics of calcium and oxygen in molten titanium and titanium-aluminum alloy. Metall. Mater. Trans. B 1996, 27, 967-972.

7. Barbosa, J.; Ribeiro, C.S.; Monteiro, A.C. Influence of superheating on casting of $\gamma$-TiAl. Intermetallics 2007, 15, 945-955.

8. Kuang, J.P.; Harding, R.A.; Campbell, J. Investigation into refractories as crucible and mould materials for melting and casting $\gamma$-TiAl alloys. Mater. Sci. Technol. 2000, 16, 1007-1016. 
9. Jia, Q.; Cui, Y.Y.; Yang, R. Intensified interfacial reactions between $\gamma$-titanium aluminide and $\mathrm{CaO}$ stabilised $\mathrm{ZrO}_{2}$. Int. J. Cast Met. Res. 2004, 17, 23-27.

10. Nowak, R.; Lanata, T.; Sobczak, N.; Ricci, E.; Giuranno, D.; Novakovic, R.; Holland-Moritz, D.; Egry, I. Surface tension of $\gamma$-TiAl-based alloys. J. Mater. Sci. 2010, 45, 1993-2001.

11. Cui, R.J.; Gao, M.; Zhang, H.; Gong, S.K. Interactions between TiAl alloys and yttria refractory material in casting process. J. Mater. Process. Technol. 2010, 210, 1190-1196.

12. Teodoro, O.; Barbosa, J.; Naia, M.D.; Moutinho, A.M.C. Effect of low level contamination on TiAl alloys studied by SIMS. Appl. Surf. Sci. 2004, 231, 854-858.

13. Sung, S.Y.; Kim, Y.J. Modeling of titanium aluminides turbo-charger casting. Intermetallics 2007, $15,468-474$.

14. Fu, P.X.; Kang, X.H.; Ma, Y.C.; Liu, K.; Li, D.Z.; Li, Y.Y. Centrifugal casting of TiAl exhaust valves. Intermetallics 2008, 16, 130-138.

15. Yang, R.; Cui, Y.Y.; Dong, L.M.; Jia, Q. Alloy development and shell mould casting of $\gamma$-TiAl. J. Mater. Process. Technol. 2003, 135, 179-188.

(C) 2015 by the authors; licensee MDPI, Basel, Switzerland. This article is an open access article distributed under the terms and conditions of the Creative Commons Attribution license (http://creativecommons.org/licenses/by/4.0/). 